\title{
Study on Harmonic Suppression and Hybrid Series Active Power Filter
}

\author{
Xiangfei Meng ${ }^{a}$, Xin $\mathrm{Li}^{\mathrm{b}}$, Huigang $\mathrm{Xu}^{\mathrm{c}}$ \\ Changshu Institute of Technology, School of Electrical and Automation Engineering, Changshu \\ 215500, China \\ aEmail: mxf0316@163.com, ${ }^{\mathrm{b}}$ Email: Ix@cslg.cn, ${ }^{\mathrm{c} E m a i l: x h g @ c s l g . c n ~}$
}

\begin{abstract}
Keywords:Harmonic Suppression ; Passive power filter ; Active power filter ; MATLAB simulation.
\end{abstract}

Abstract. This paper focuses on the generation and harm of power harmonic, and different measures on harmonic treatment. Analysis the Harmonic Suppression measures of Hybrid Series Active Power Filter. Result shows that the Hybrid Series Active Power Filter devices has the capacity advantages , which is appropriate to the compensation of large-capacity harmonic source. From the experiment results, the kind of mixed-type filters results well.

\section{Introduction}

In recent years, the widespread application of nonlinear load caused serious pollution to the power quality. The harmonic of power system is becoming more and more serious. There is a traditional method of eliminating harmonic which is incorporated into the passive LC filter in power system. Although the cost of passive LC filter is very low, it has many shortcomings. For example, the compensation performance is affected by the impedance of power system, and it's easy to produce to resonance accident with power system, and it cannot realize dynamic compensation of harmonics. Active power filter is a relatively new device for eliminating harmonic and achieving.

\section{The Generation and Harm of Power Harmonic}

The fundamental of harmonic generation is caused due to the nonlinear load. When the current through the load, the relationship wasn't linear with the voltage applied, the formation of non sinusoidal current, resulting in harmonic. When source impedance exists in the actual system, the distortion current will cause a voltage drop in the impedance, resulting in distortion of the voltage. The reactive power compensation. Through a certain algorithm to detect harmonic current in load side need, it gives corresponding harmonic current, so as to achieve the goal of compensation. It uses a certain algorithm to detect the harmonic current which is the load need, and it gives corresponding harmonic current, so as to achieve the goal of compensation. Current system will be close to an ideal sine wave after compensation. Combined with passive LC filter using hybrid active power filter on the one hand it can well improve the passive LC filter filtering effect, on the other hand, it relative to the separate use of active filter and its installed capacity is greatly reduced. In this paper, the series hybrid active power filter technology is studied. voltage distortion will affect all of the loads. In the system the main harmonic source can be divided into two categories.

(1) Power electronic device contains a semiconductor nonlinear components of the harmonic sources, such as various rectifier equipment, AC voltage regulator, variable current equipment, DC drive equipment, rectifier, PWM frequency converter, phase modulation frequency converter and modern industrial facilities for energy conservation and control of power electronic equipment and so on.

(2) Nonlinear device contains electric arc and ferromagnetic of the harmonic sources, such as AC electric arc furnace, AC Welder, fluorescent lights, generators, transformers and ferromagnetic resonance equipment and so on. 
Household appliances belong to the above two types of harmonic sources. Their capacity is small, but the quantity is large. For this reason, it is a harmonic source which can't be ignored. All of these make the distortion of the power system voltage and current waveform, resulting in a higher harmonic.

The harmonic voltage and harmonic current to the damage of power system can be broadly in the following aspects.

1) A large number of harmonics reduce the efficiency of power generation, transmission and electrical equipment and add additional harmonic loss of components.

2) Harmonics affect the normal operation of various electrical devices.

3) In the power system harmonic will cause partial parallel resonant and series resonance, which magnify harmonic, increase additional loss and fever and cause device failure.

4) Harmonic can result the relay protection and automatic device misoperation and make electric measuring instrument measurement inaccurate.

5) Harmonic can produce interference or noise on the nearby communication system, so it reduces the communication quality.

There are three main methods of harmonic treatment.

1) By the end of governance.

2) Starting from the equipment or system influenced by harmonics.

3) Improve their anti-jamming ability.

\section{Harmonic Suppression}

The main means of harmonic suppression is divided into two types: passive filter and active filter. With the help of full control power electronic switching devices, active power filter is an important means to restrain the harmonics. Active power filter is divided into series and parallel.

Shunt active power filter is a kind of the earliest use of active power filter. Previously full control power electronic device is high price, small capacity, slow speed and low voltage withstand level, so the compensation capacity of shunt active power filter have been relatively small.Load is the harmonic source. The main circuit of active power filter includes current transformer, inductor connected to transformer and DC energy storage element in Fig. 1. The main circuit of active power filter is in parallel with the load connected to power system, so it is called the parallel type. This is the most basic form of active power filter, and it is one of the most used.

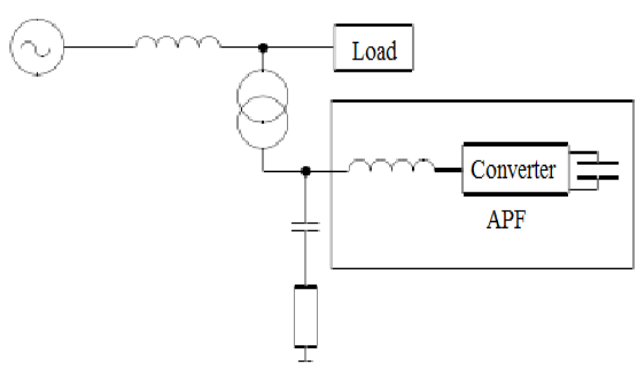

Fig. 1 Shunt active power filter

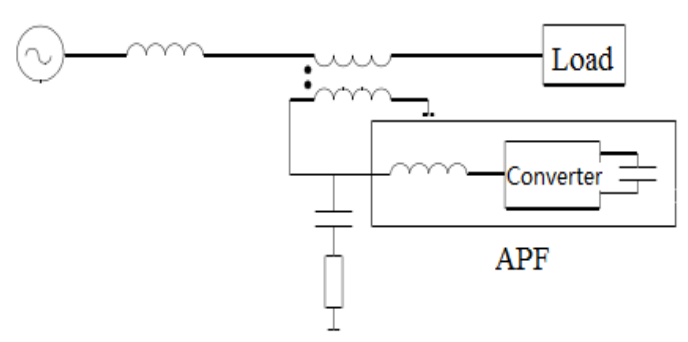

Fig. 2 Series active power filter

The characteristic of the series active power filter is active power filter as a voltage source in series between the power supply and harmonic sources. In most cases, the shunt active power filter is suitable for compensating current type harmonic source load, and the voltage type harmonic source load compensation effect is not very ideal.

The voltage type harmonic source load is rectifier circuit containing large capacitor filter in DC side. In the past because of the rectifier circuit capacity was small and it scattered distribution, the harmonic pollution has failed to cause enough attention. As frequency inverter, switching power supply, UPS and the application of electronic rectifier is increasing, voltage type harmonic source load does not allow ignore, so series active power filter is proposed. Series active power filter output offset voltage, 
offset the harmonic voltage generated by the load, make power point voltage wave form a sine wave in Fig. 2.

\section{Hybrid Series Active Power Filter}

With the condition of power harmonic becoming more and more serious, defects of the traditional passive power filter scheme has become obvious more and more. Most of the applications of active power filters are parallel. Shunt active power filters need the device with large capacity, so the investment and operation cost is very high. This paper proposes hybrid series active power filter to reduce harmonic. Hybrid series active power filter mainly composed of a small capacity of active power filter cascaded in the power system and a pair of parallel LC passive power filters. The structure of the system is shown in figure 3 .

As it shows in figure 3, in order to eliminate most of harmonics caused by the electrical load, the passive power filters consist of five times, seven times filters and a high-pass filter. Hybrid series active power filter has the advantage of both active power filters and passive power filters, and it can effectively compensate harmonics reactive power in high power applications, moreover, it can overcome the shortages of LC filters vulnerable to affected by the power system impedance to resonate.

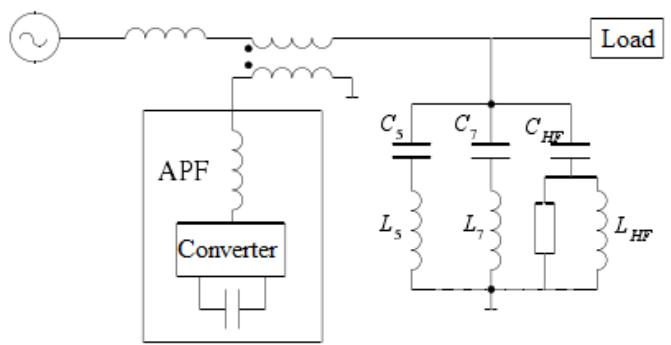

Fig.3 Series hybrid active power filter power filter

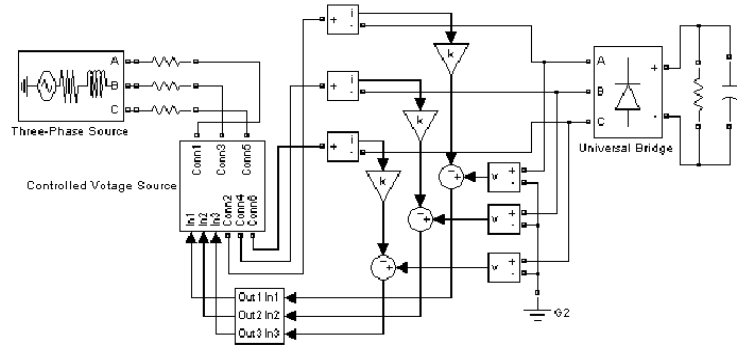

Fig.4 The simulation model of series hybrid active

\section{Matlab Simulation Experriment}

A capacitive load system with Three-phase $/ 50 \mathrm{~Hz}, 380 \mathrm{~V} / 10 \mathrm{VA}$ is simulated and analysed which is based on Hybrid series active power filter. Figure 4 is the simulation model of Hybrid series active power filter.

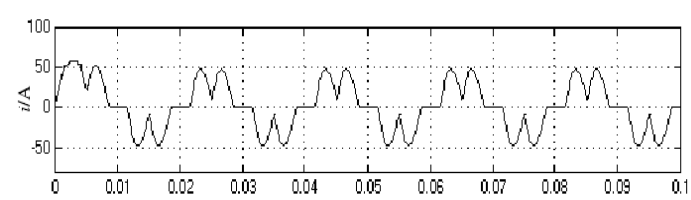

a) The grid current without APF

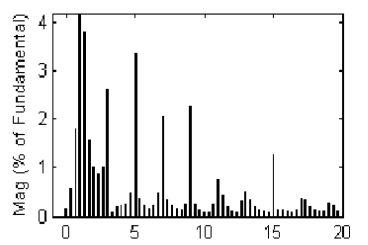

c) Current frequency without APF

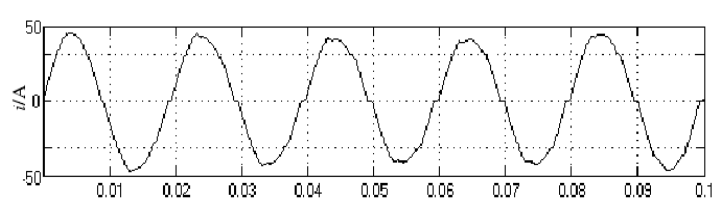

b) The grid current with APF

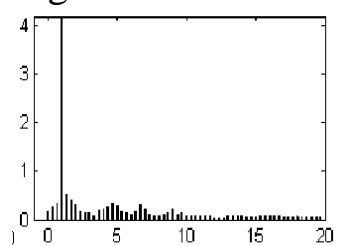

d) The APF current spectrum

Fig.5 The simulation results of the series hybrid active power filter

As can be seen from the figure 5-c), the system without active power filters has harmonics; the harmonics have greatly reduced when the system has active power filters. When the system is compensated with active power filters, the current Total Harmonic Distortion factor (THD) in the 
testing system is decreased from $46.89 \%$ to $3.85 \%$, and it proves that the Hybrid series active power filter can effectively eliminate current harmonics in power grid.

\section{Conclusion}

Besides the advantages of active power filters, the Hybrid series active power filter has the characteristic of small capacity of active power device, low cost of investment and operation, and it can apply to the situation of large capacity harmonics compensation. The experiment shows that the Hybrid series active power filter eliminates harmonics effectively.

\section{Acknowledgements}

This paper is supported by the Jiangsu Province research joint innovation fund project (NO. BY2014075)

\section{References}

[1] Wang Zhaoan, Yang Jun, Liu Jinjun. The harmonic elimination and reactive power compensation. Beijing: Mechanical Industry Press, 2014:23 30

[2] Lang Weichuan, power system harmonic harm and its protection countermeasures. High voltage engineering, 2012, 28 (6):30 39

[3] Hu Junda. Harmonics in power system produce, harm and suppression. Hubei electric power, 2013, $27(5): 2 \sim 3$

[4] Li Zhanying, Ren Zhen, Yang Zeming. Survey of active power filter and its application. Power system technology, 2014, 28 (22):40 43

[5] Zhong Lin, Wang Feng. MATLAB simulation technology and Application guide. Beijing: National Defence Industry Press, 2010

[6] George J Wakileh. Harmonic in power system [M]. Beijing: Mechanical Industry Press, 2003 